\title{
Ergonomic Evaluation of Workstations in Industry with Emphasis on Economic Considerations (Case Study: Automotive Industry)
}

\author{
Hasan Sadeghi Nayeeni ${ }^{1}$, Mohammad Zolfaghari ${ }^{2 * i D}$
}

1. Associate Professor, Department of Industrial Design, School of Architecture and Environmental Design, Iran University of Science and Technology, Tehran, Iran

2. MSc Student, Department of Industrial Design, School of Architecture and Environmental Design, Iran University of Science and Technology, Tehran, Iran

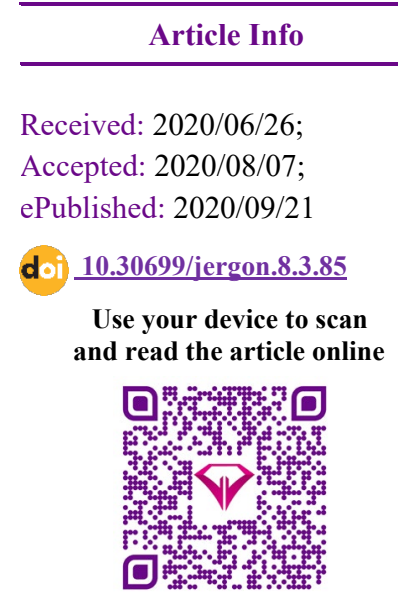

Corresponding Author Mohammad Zolfaghari MSc Student, Department of Industrial Design, School of Architecture and Environmental Design, Iran University of Science and Technology, Tehran, Iran Email:

Zolfaghari_m@cmps2.iust.ac.ir

\section{ABSTRACT}

Background and Objectives: Annually, a percentage of the profits from the sale of goods and services by producers are spent on costs of musculoskeletal disorders due to non-compliance with ergonomic conditions. These costs are not favorable for organizations and employees and in most cases، ergonomic risk factors affect the quality of life of employees.

Methods: The present field study was conducted as a census on 193 workers with medical records in one of the domestic automotive industries on December 2018. The highest prevalence of musculoskeletal disorders belonged to 16 workers, so their workstations were analyzed. Nordic questionnaire and interviews with workers were the tools of data collection. Each of the selected workstations were analyzed with OWAS method after taking photos and videos from different jobs.

Results: The results showed that three work stations from the viewpoint of Action Categories are at the level of three, three work stations at the level of two and one station at the level of one; then the costs of incidence and treatment and related actions due to establishing ergonomic conditions were calculated.

Conclusion: Workstations analysis, preventive actions and also designing a process to reduce the musculoskeletal abnormalities of the staff, which results in ergonomic conditions, compared with the cost of incidence and treatment of musculoskeletal complications is cost-effective for this automotive industry. Cost

Keywords: Ergonomics, Musculoskeletal Disorders, OWAS, Nordic Questionnaire,

Copyright (C) 2020, This is an original open-access article distributed under the terms of the Creative Commons Attribution-noncommercial 4.0 International License which permits copy and redistribute of the material just in noncommercial usages with proper citation.

\section{How to Cite This Article:}

Sadeghi Naeini H, Zolfaghari M. Ergonomic Evaluation of Workstations in Industry with Emphasis on Economic Considerations (Case Study: Automotive Industry). Iran J Ergon. 2020; 8 (3):85-93 
ارزيابى اركونوميك ايستگًاههاى كار در صنعت با تأكيد بر ملاحظات اقتصادى

(مورد مطالعه: صنعت خودرو)

حسن صادقى نايينى '، محمد ذوالفقارى (D)

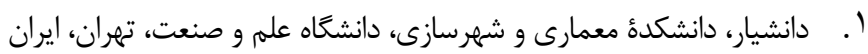

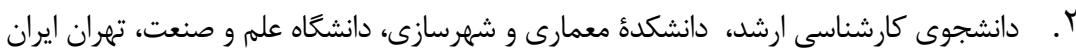

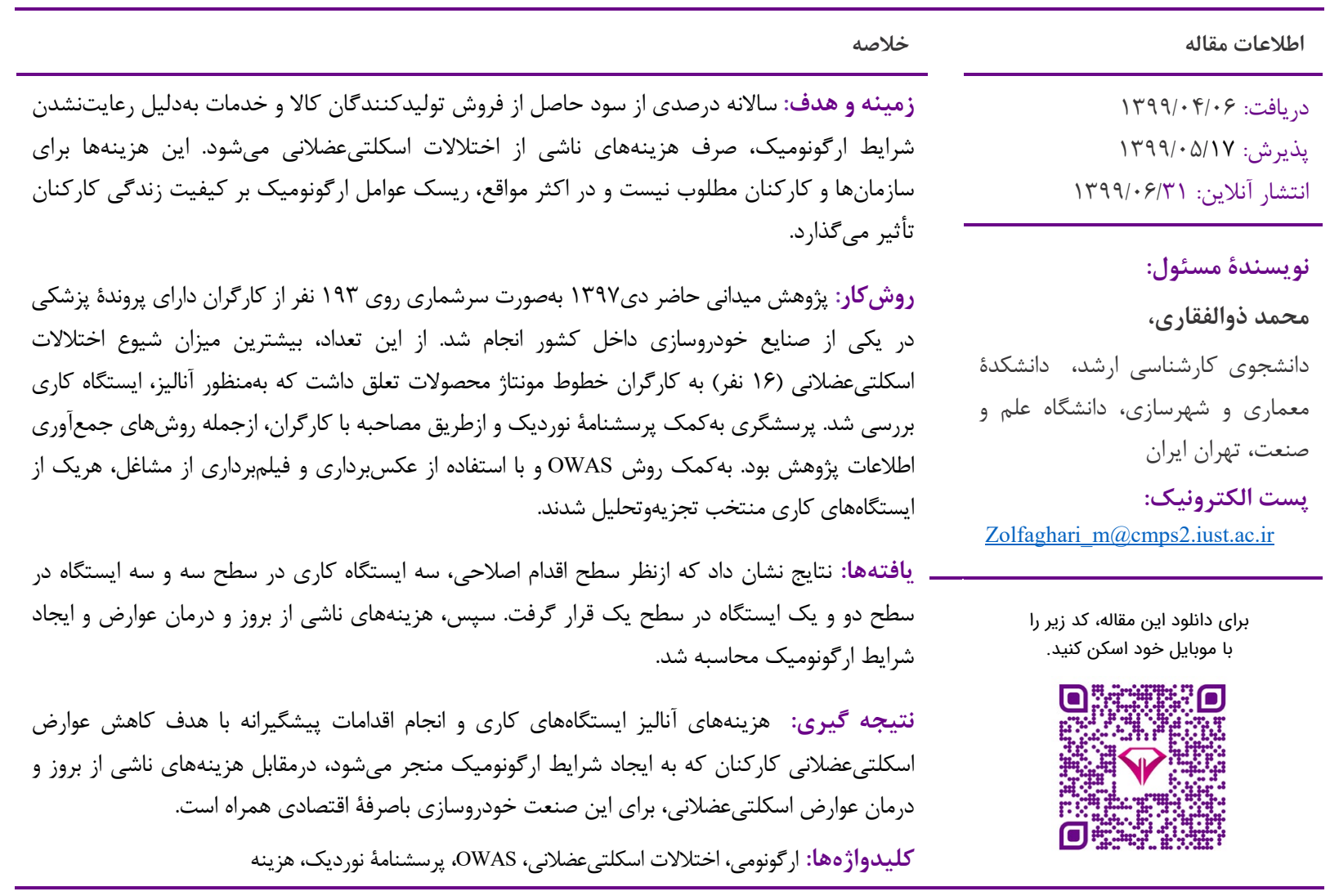

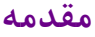

صنايع خودروسازى ازجمله صنايع رونقبخش اقتصادى است [r]. با اينكه در خطوط توليد اين صنايع از رباتهاى صنعتى بهايعاى رنائ انسان

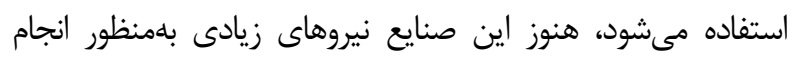

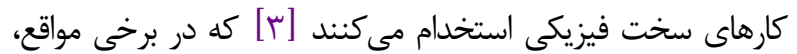

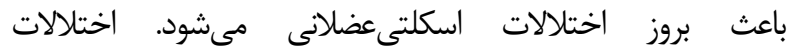

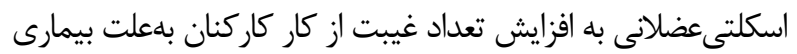

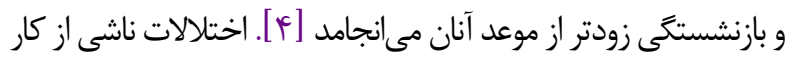

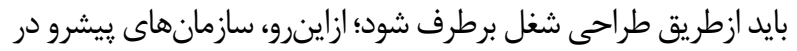

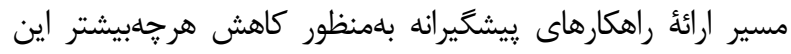
اختلالات و ايجاد شرايط اركونوميك كارى تام برمى اردارند.
اختلالات اسكلتىعضلانى يكى از مشكلات عمدة كاركنان و

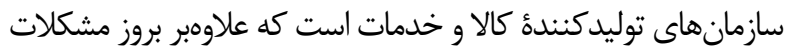

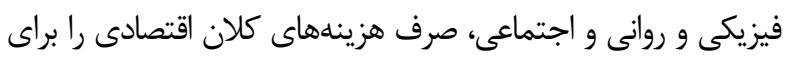
كاركنان و سازمانها در يى دارد. براساس تعريف مؤسسأ ملى ايمنى و

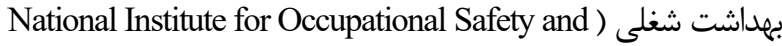
Health)، اختلالات اسكلتىعضلانى از كروهى از ساختارها شامل

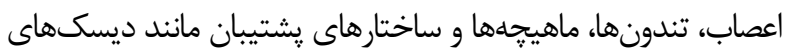
بينمهرهاى تشكيل مىشوند. گستره اين اختلالات وسيع است؛ بلصورتى كه طيف آن از علائم خفيف تا دردهاى شديد و مزمن و حتى

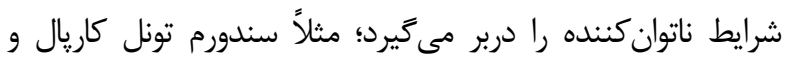
سندورم كشيدگى كردن و كمردرد [ [ ]. 
مورد حادثة شغلى رخداده در سال | وسا برآورد شد. در اين يزوهش،

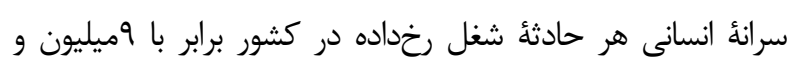

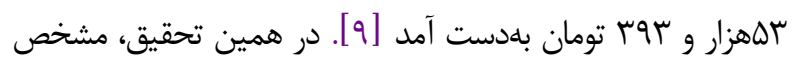

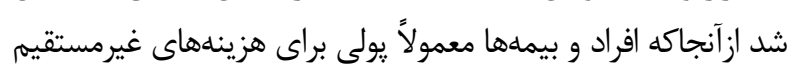

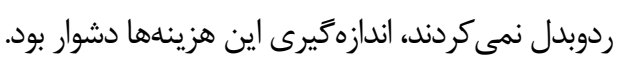

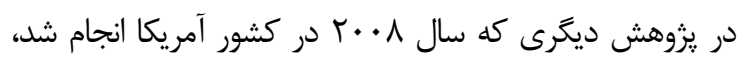

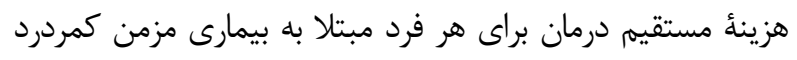
غرمستقد JVVIVT

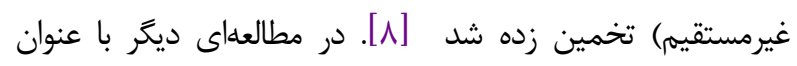

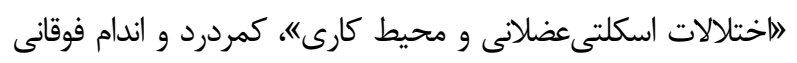

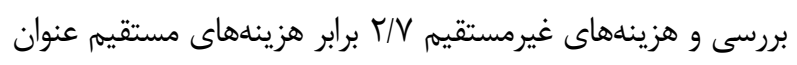

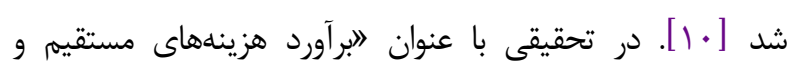

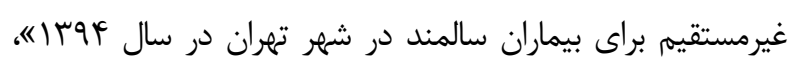

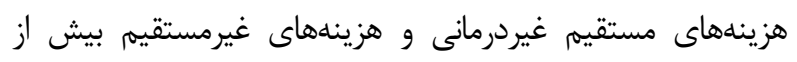

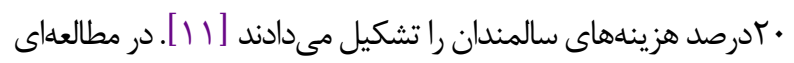

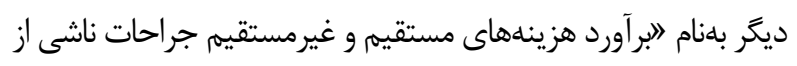

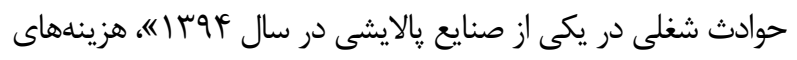

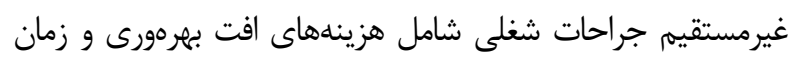

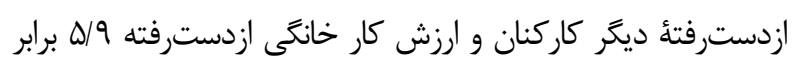

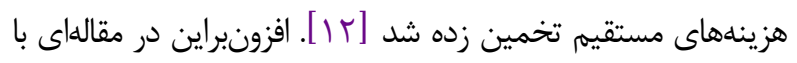

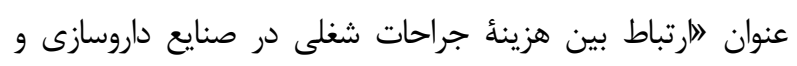

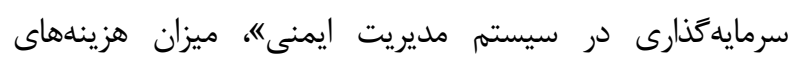

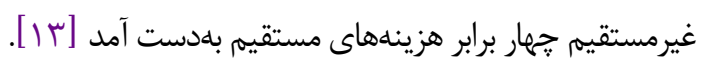

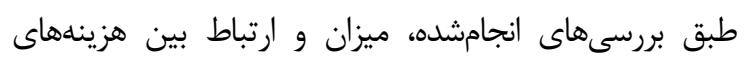

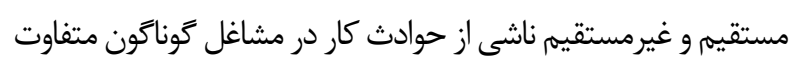

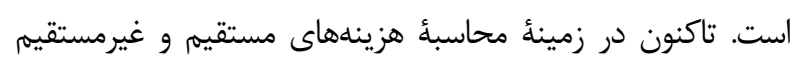

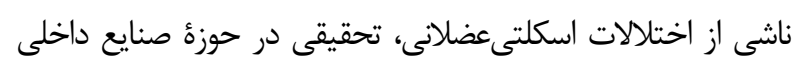

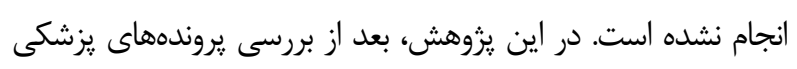

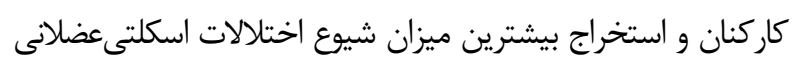

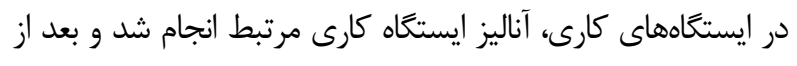

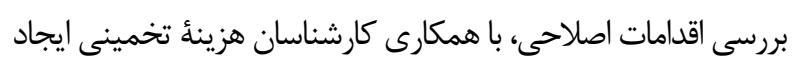

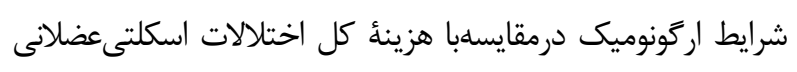

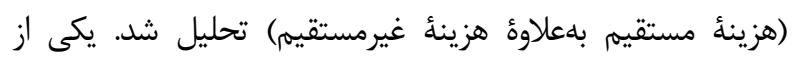
محدوديتهاى تحقيق تفكيكنشدن مبالغ يرداختى سازمان تأمين

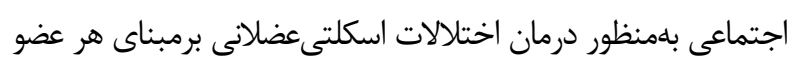

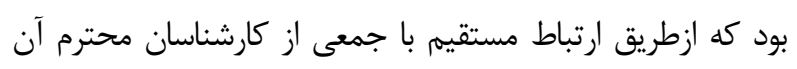

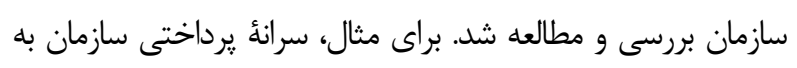

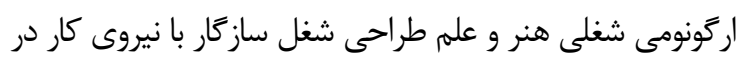

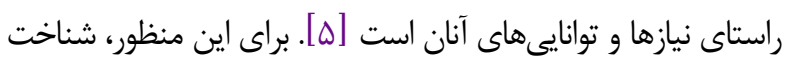

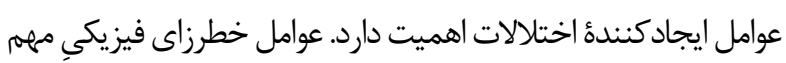

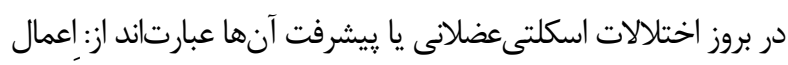

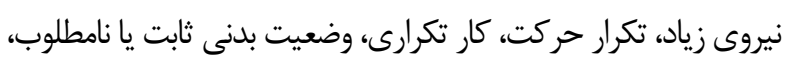

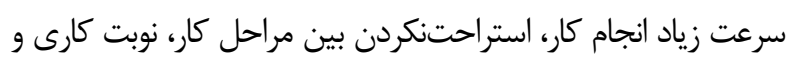

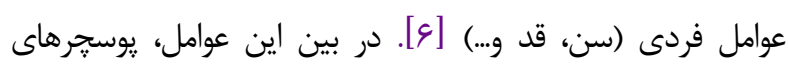

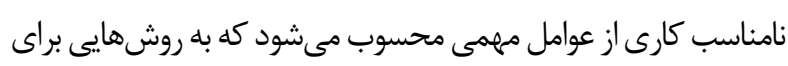

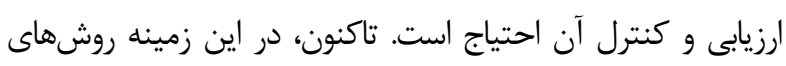

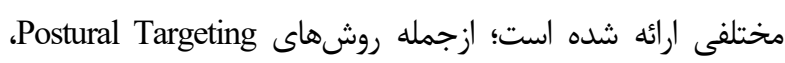

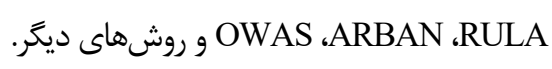
Ovako Working Posture Assessment مخف دوش OWAS روش ازي جمله روشهاى يركاربرد براى آناليز يوسجرهاى كارى است.

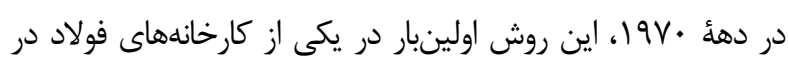

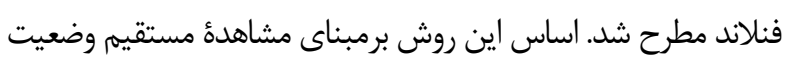

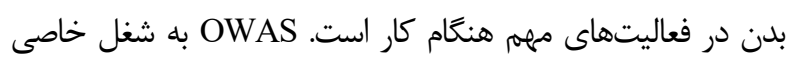

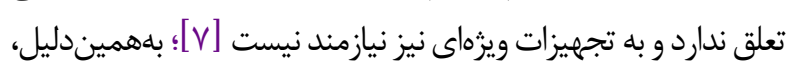

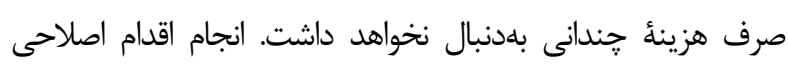

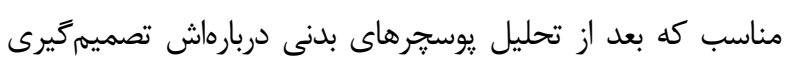

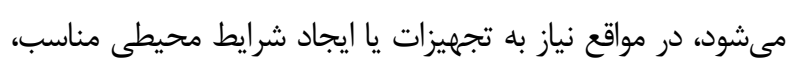

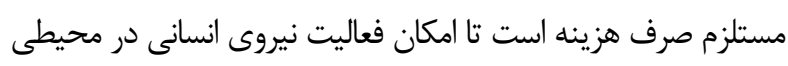
اركونوميك فراهم شود.

در بسيارى از مواقع، انجامندادن اقدام اصلاحى مناسب زميناساز

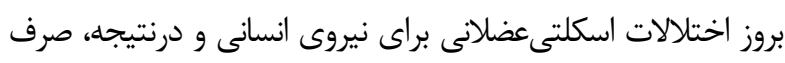

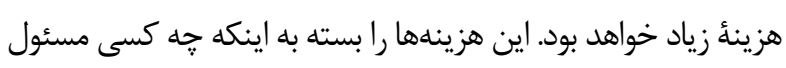

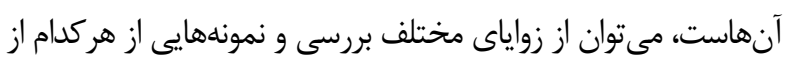

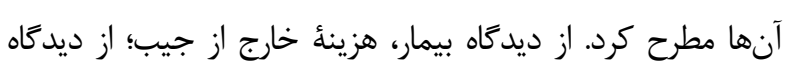

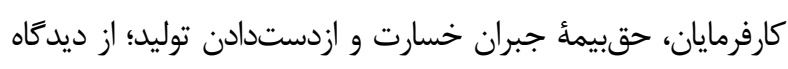

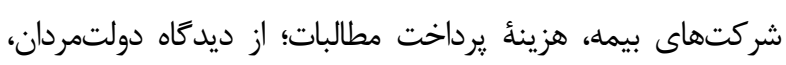

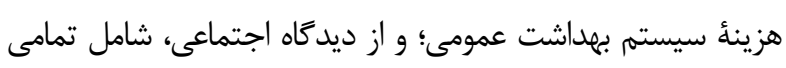

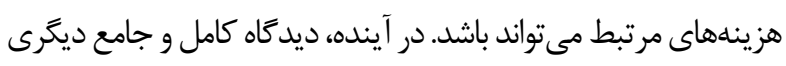

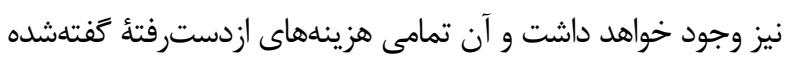

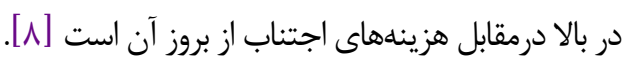

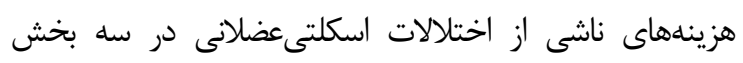

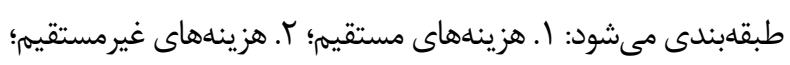

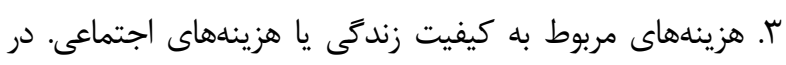

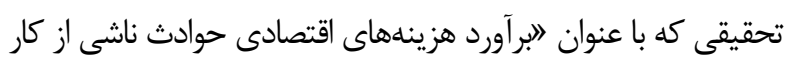

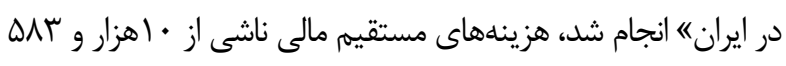




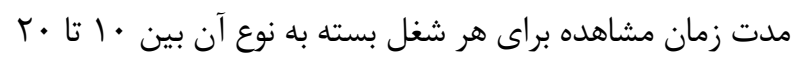

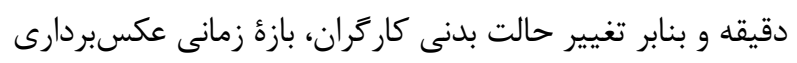

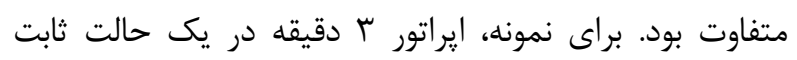

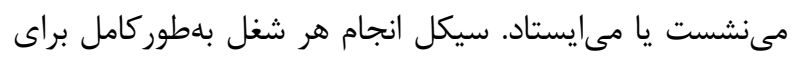

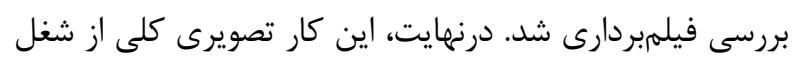

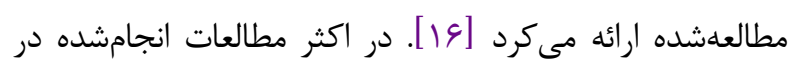

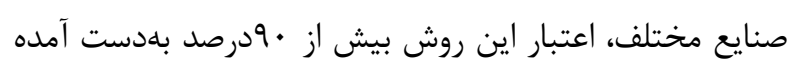

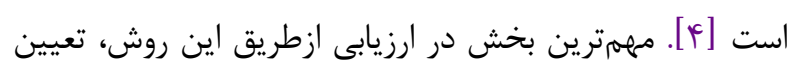

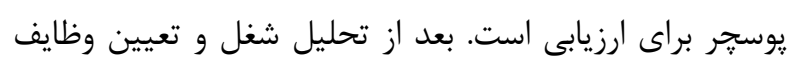

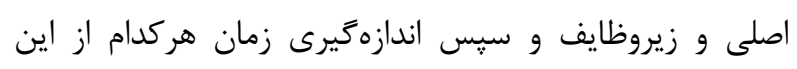

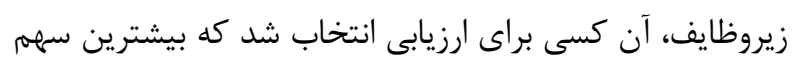

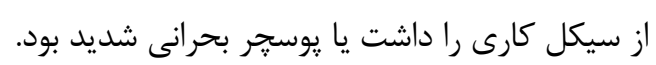
بعد از تعيين اولويت انجام اقدامات اصلاحى، راهي راهكارهاي ممكن در كميتههاى تخصصى متشكل از كارشناسان ساخت ابزار

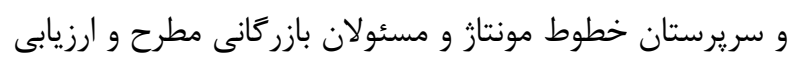

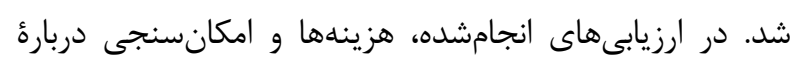

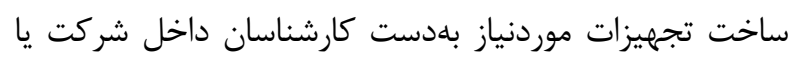
تأمين آن از خارج از كشور و كيفيت ساخت داخلى آنى آن تحليل شد. هزينههاى ناشى از بروز اختلالات اسكلتى عضلانى را مى تارتوان در حالات كلى در سه بخش بررسى كرد:

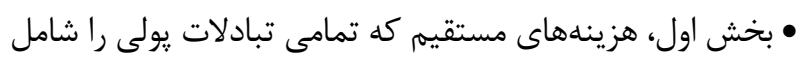

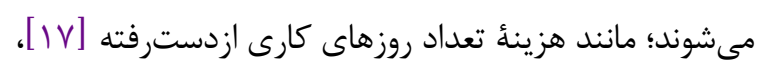

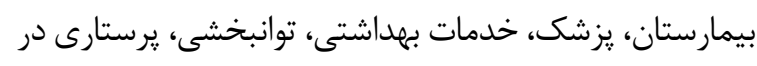

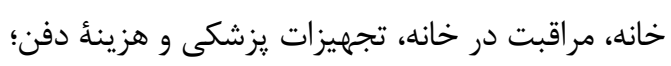

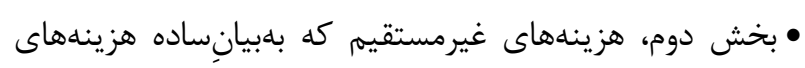

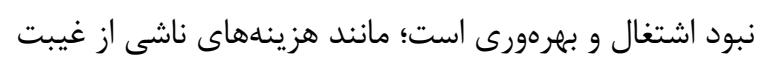

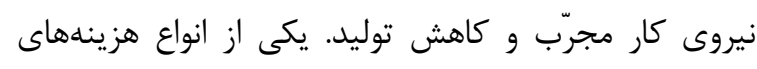

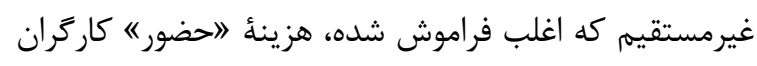

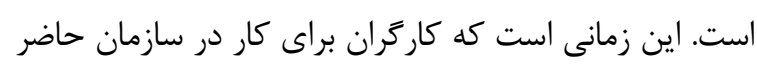

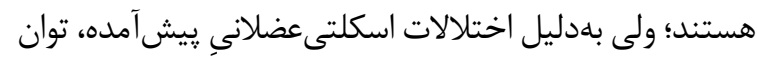
توليدشان كاهش يافته است [1/1]. حضور كاركران مبتلا به اختئ

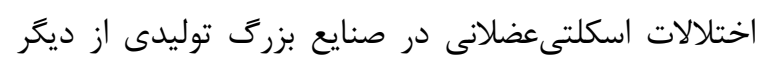

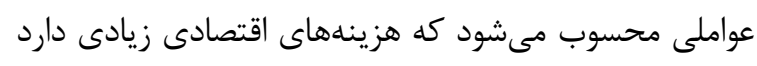
و شناسايى و محاسبةٌ آن بلدراحتى مقدور نيست؛

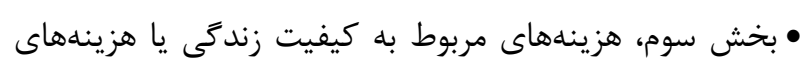

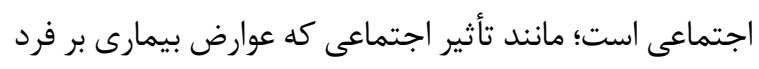

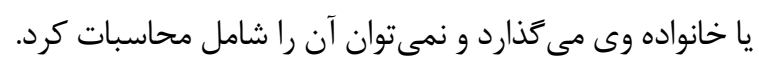

بيماران براى درمان اختلالات اسكلتى عضلانى مرتبط با درمان كمردرد

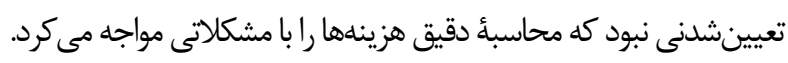

\section{روش كار}

يزوهش ميدانى حاضر سال \qجا بلهصورت سرشمارى روى

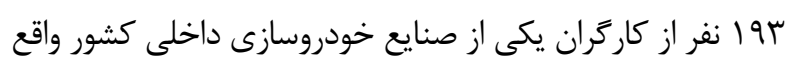

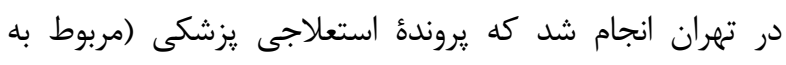

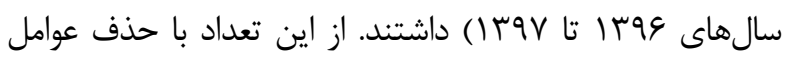

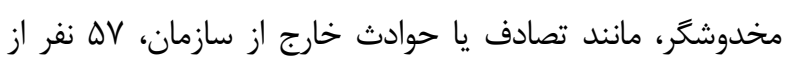

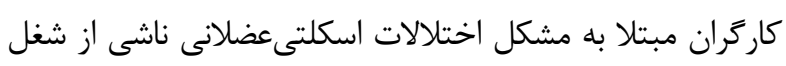

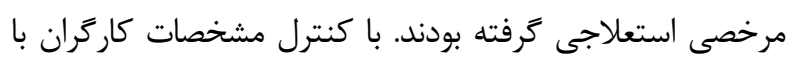

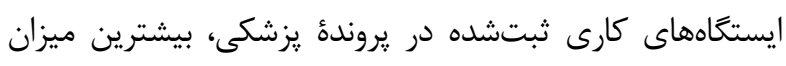

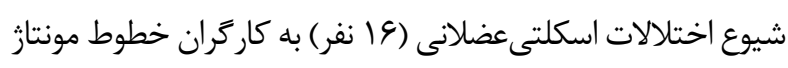

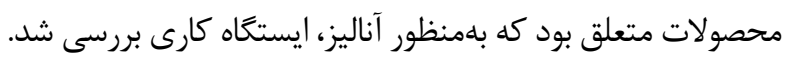

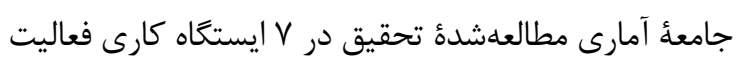

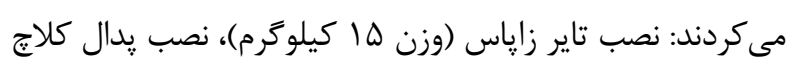

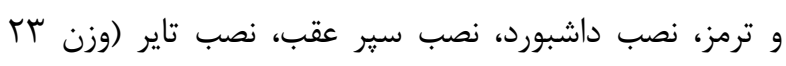

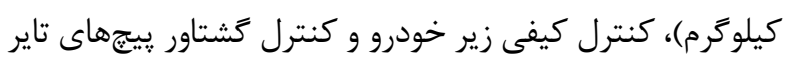

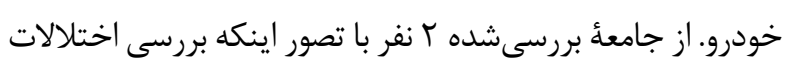

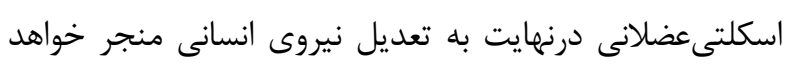

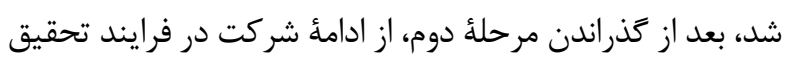

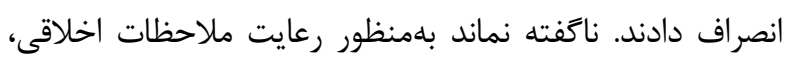

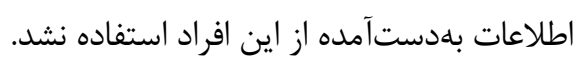

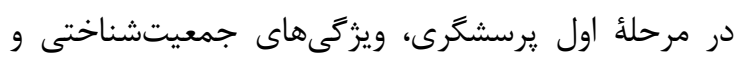

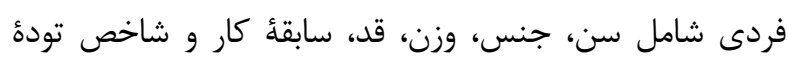

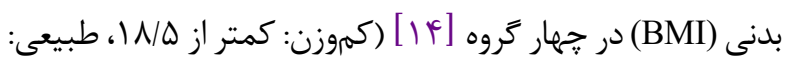

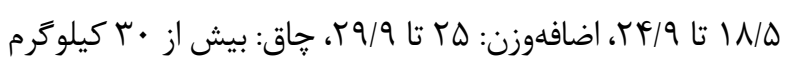

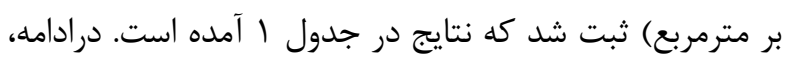

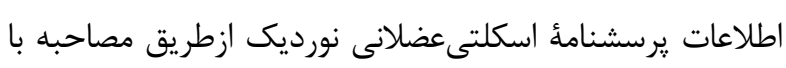

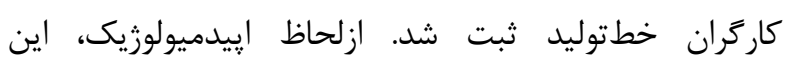

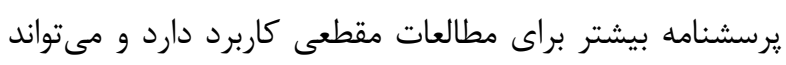

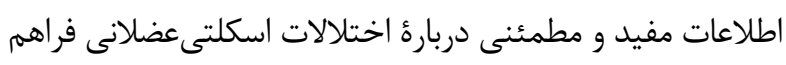

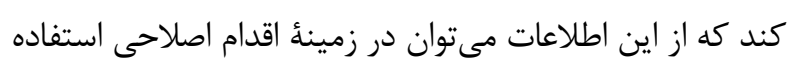

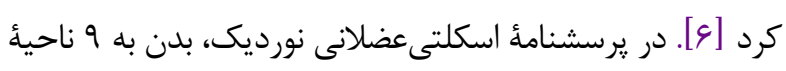

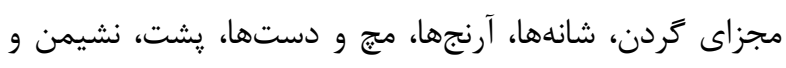

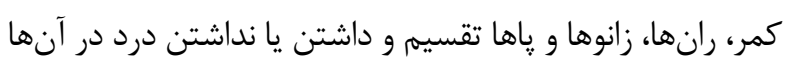

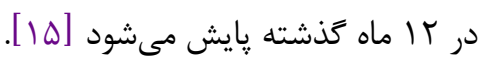

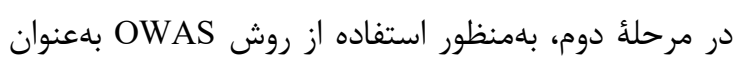
شيؤ ارزيابى يوسجر، شغلهاى هر ايستكاه زيرنظر كرفته شد. 


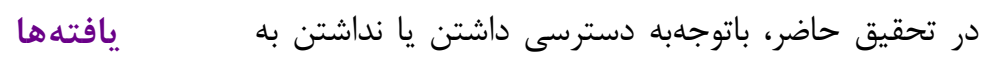

بعد از بروز اختلالات اسكلتىعضلانى، كارگران يا ترى كار

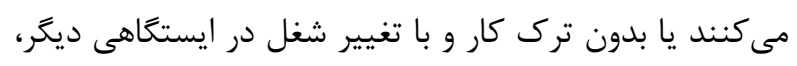

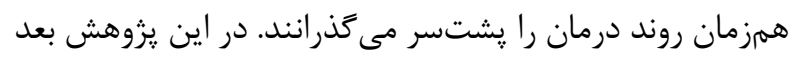

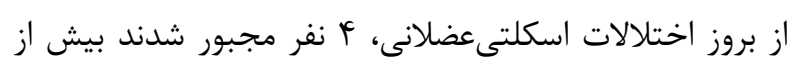
دو ماه ترك كار كنند و بعد از باز خشت به كار، در ايستخاه ديخر

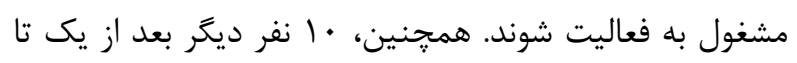

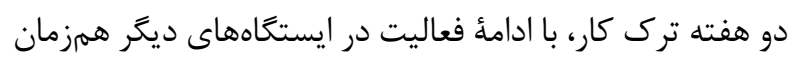

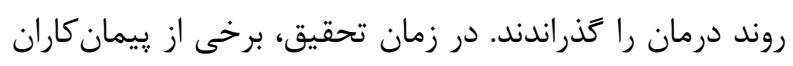

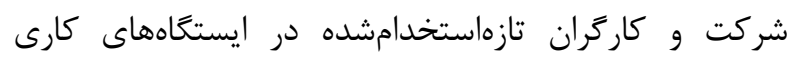
منتخب مشغول به فعاليت بودند. در جداول r و و ب نتايج

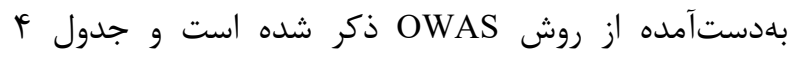
ييشنهاد متخصصان و هزينُٔ برآوردشده را بررسى مى كنند. جدول ه محاسبة هزينهُ مستقيم و غيرمستقيم اختلالات

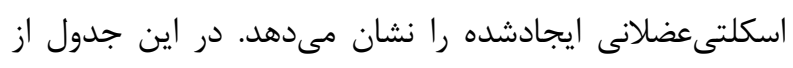

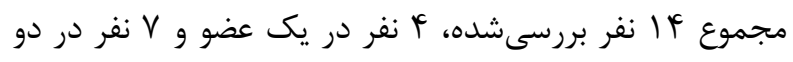
عضو و ا نفر در سه عضو احساس درد مى كردند كه تعداد كل اختلالات الr عدد درج شده است.
تمامى اطلاعات مرتبط، تنها بخشى از هزينههاى ذكرشده محاسبه كردنى بود. در بخش هزينههاى مستقيم، هزينههاى روزهاى كارى ازدسترفته، بيمارستان (اقامت و بيهوشى)، يزشك (تعرفه

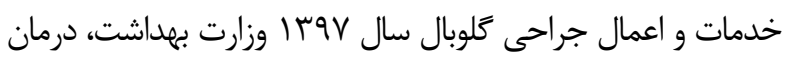
و آموزش) و توانبخشى محاسبه شد. هزينهُ تعداد روزهاى كارى

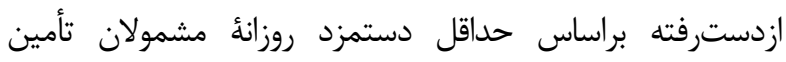
اجتماعى در روز براى سال لو \ا از وبسايت رسمى سازمان مبلغ •rV.

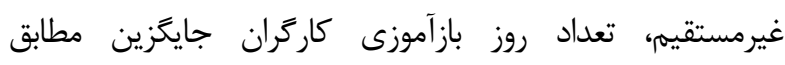
استانداردهاى داخلى در صنعت بررسىشده · ب روز براى هر ايستخاه

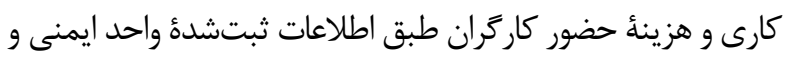
بهداشت شركت يك تا دو هفته باتوجهبه شدت عارضه محاسبه شد. درنهايت، كل هزينههاى ايجاد شرايط ارگونوميك درمقايسهبا هزينه ناشى از اختلالات اسكلتى عضلانى بررسى شد.

جدول (. مشخصات جمعيتشناختى كاركران منتخب (تعداد=و 1 نفر)

\begin{tabular}{|c|c|c|c|c|}
\hline انحر افِمِعيار & حداكثر & حداقل & ميانگين & متغير \\
\hline$D / \Lambda F$ & FT & TF & r & سن \\
\hline$r / \Delta Q$ & Tr/l & Tt & $r \& / \Delta \Delta$ & 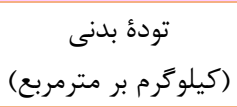 \\
\hline$\tau \Delta / r \Delta$ & ris & c. & $119 / 0$ & سابقة كار (ماه) \\
\hline
\end{tabular}

جدول r. فراوانى تجمعى ناراحتى هريك از اندامها و سطح اقدام اصلاحى براساس روش OWAS

\begin{tabular}{|c|c|c|c|}
\hline اقدام اصلاحى & درصد فراوانى تجمعى & وضعيت & 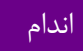 \\
\hline 1 & א/ F/ ادرصد & ستون فقرات كشيده و مستقيم & \multirow{4}{*}{ تنه } \\
\hline r & 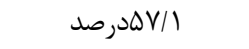 & ستون فقرات خميده & \\
\hline & & كمر در حال جرخش & \\
\hline r & ا & كمر خميده و در حال خرخش & \\
\hline \multirow[t]{2}{*}{1} & أ & هر دو باز و پايينتر از ارتفاع شانه & \multirow{3}{*}{ 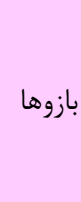 } \\
\hline & & يكى از بازوها در ارتفاع شانه يا بالاتر & \\
\hline r & K א أ ادرصد & هر دو بازو در ارتفاع شانه يا بالاتر & \\
\hline r & ل & نشسته & يُاها \\
\hline
\end{tabular}




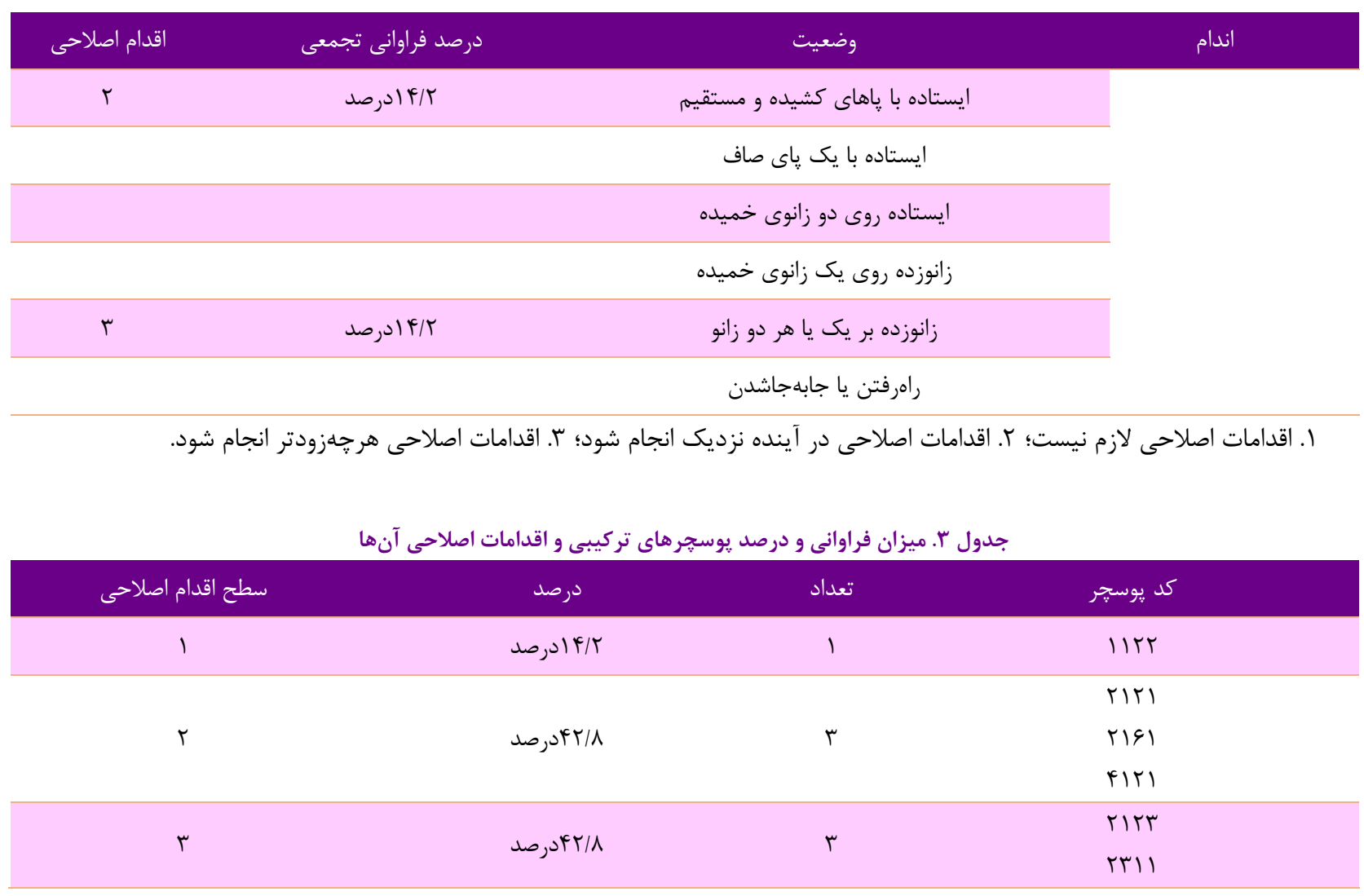

جدول F. يِيشنهادهاى متخصصان شركت درباره طراحى ايستكًاههاى كارى مطالعهده

\begin{tabular}{|c|c|c|c|c|c|}
\hline تخمين هزينه (ريال) & روش & تجهيزات & اصلاحى اقدام & وظيفة كارى & 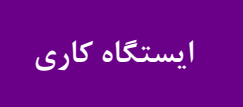 \\
\hline · & كردش شغلى & & 1 & صاز دابدجايى تاير با وزن ها صيلوكرم & نصب تاير زاياس \\
\hline · & كردش شغلى & & r & 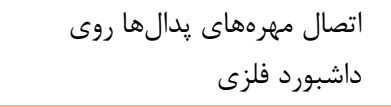 & نصب يدال كلاج و \\
\hline 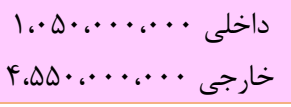 & & منىيليتور داشبورد & r & اتصال بيجهاى داشبورد روى بدنه & نصب داشبورد \\
\hline · & & جكش ״ِلاستيكى & r & جمهرهها متاخن سير با ضربه و بستن & نصب سير عقب \\
\hline $10 \cdot r, \ldots \cdot \cdots$ & & بالانسر تاير & r & 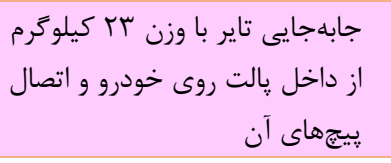 & نصب تاير \\
\hline$r \cdot \ldots \ldots, \ldots$ & & 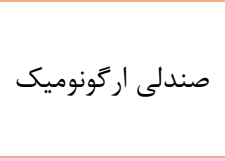 & r & 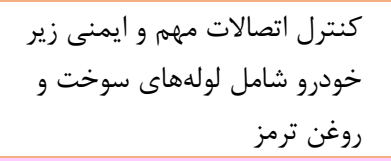 & كنترل زير خودرو \\
\hline$r \Delta \cdot \ldots \ldots$ & 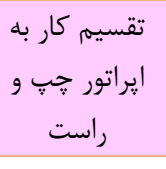 & 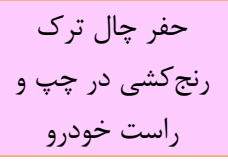 & r & كنترل كشتاور تمامى يِيجهاى تاير & ترى ريج هاى تاير \\
\hline 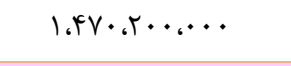 & & & \multicolumn{3}{|c|}{ مجموع (درصورتىكه منى يليتور داشبورد در داخل ساخته شود) } \\
\hline$f . q v \cdot . r \cdots . .$. & & & \multicolumn{3}{|c|}{ مجموع (درصورتى كه منى يليتور داشبورد از خارج تأمين شود) } \\
\hline
\end{tabular}


جدول ه. هزينهاى مستقيم و غيرمستقيم اختلالات اسكلتىعضلانى (ريال)

\begin{tabular}{|c|c|c|c|c|c|c|}
\hline \multicolumn{2}{|c|}{ هزينهُ غيرمستقيم } & \multicolumn{2}{|c|}{ هزينه مستقيم } & \multirow{2}{*}{ اختلالات } & \multirow{2}{*}{ تعداد روز كارى } & \multirow[b]{2}{*}{ 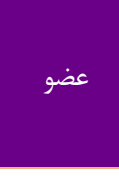 } \\
\hline حضور كارگران & باز آموزى كاركران & ازدسترفته كارى & بيمارستان و & & & \\
\hline $880 ، 185 ، 5$ & $11.111 .9 .$. & MI.11Q.rर. & FVY,IAF.... & 4 & $\wedge F$ & تردن \\
\hline $880 ، 185 ، 5$ & $600 ، 112 ، 11$ & $1 \cdot . r V I . V G$. & 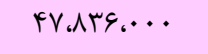 & r & rA & مج دست \\
\hline $880 ، 185 ، 5$ & $600 ، 112 ، 11$ & $\| F_{،} \wedge r \cdot r \cdot$. & 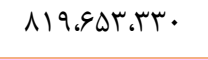 & 9 & ו. & كمر \\
\hline $940.592 ، 2$ & $600 ، 112 ، 11$ & $1 \cdot . r \vee 1 . V 9$. & FV،Arq.... & r & rA & مج يا \\
\hline $940 ، 592 ، 2$ & $600 ، 112 ، 11$ & r.DQY.qY. & $r r . q 1 \Lambda_{1} . .$. & 1 & v & شانه \\
\hline $940.592 ، 2$ & $600 ، 112 ، 11$ & 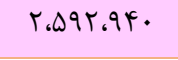 & $r r . q 1 \wedge . .$. & 1 & v & زانو \\
\hline . & $99.9 \vee \Delta .9 .$. & $|V| ، \wedge V F ، \wedge \Lambda$. & 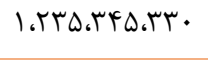 & rI & feY & مجموع \\
\hline \multicolumn{2}{|c|}{$9 \cdot . \cdot 1 r_{\cdot} \cdot 9}$. & \multicolumn{2}{|c|}{$1, t \cdot R \cdot T t \cdot .41$} & \multicolumn{3}{|c|}{ هزينهای مستقيم و غيرمستقيم } \\
\hline \multicolumn{4}{|c|}{ I.FQV.KMT.TV. } & \multicolumn{3}{|c|}{ كل هزينهها } \\
\hline
\end{tabular}

در ايستگًاه نصب سير عقب، بايد از جكشى استفاده مىشد

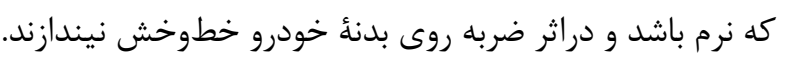

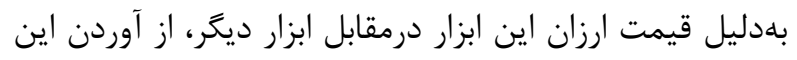

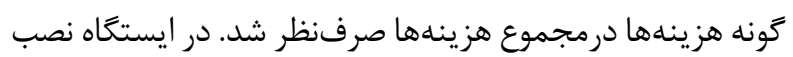

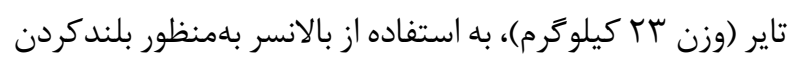

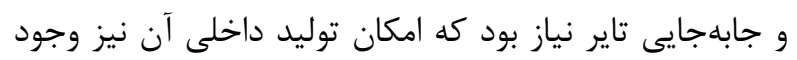

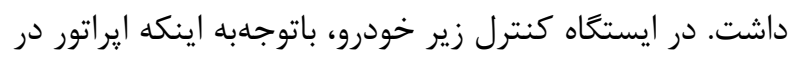
حالت نشسته بايد هر دو دست خود را براى طولانىمدت بالاى بالي

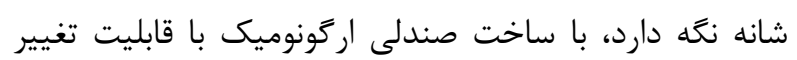

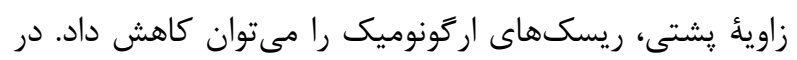

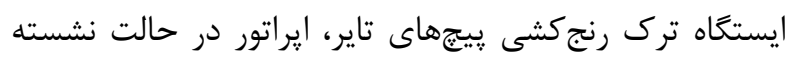

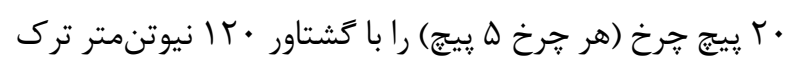

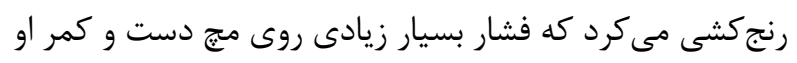

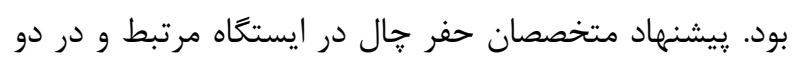
طرف خودرو بلهورتى كه ايراتور بتواند در حالت ايستاده كار

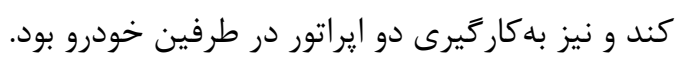

\section{بحث}

براساس اعلام سازمان بينالمللى عار، كشورهاى

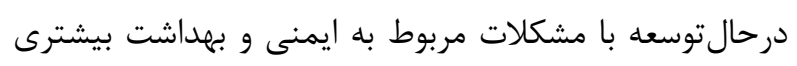
درمقايسهبا كشورهاى توسعهيافته دستوينجه نرم مى كن بند؛

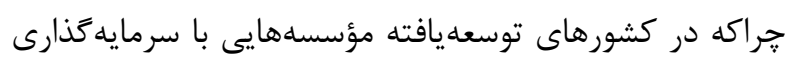
مالى مناسب براى جمعآورى اطلاعات مربوط به ايمنى و و

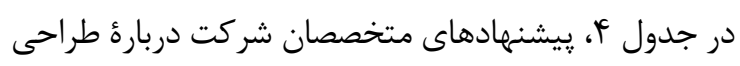
ايستخاههاى كارى مطالعه شده آمده است. در ايستخاه نصب تاير

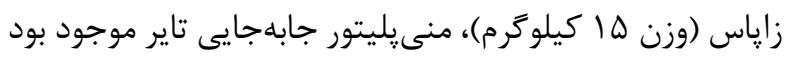

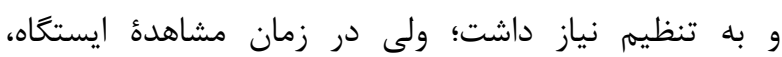
قابلاستفاده نبود و ايراتور خطمونتاز با دست تاير را جابهجا مى كرد. بهدليل اينكه زمان انجام فعاليت بسيار كوتاه و تعداد

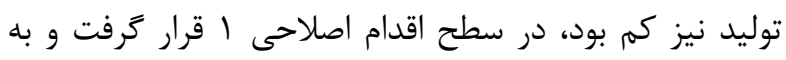

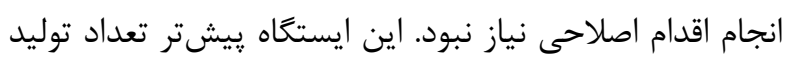
بسيار زيادى داشت. در ايستغاه نصب يدال كلاج و ترمز، نظر متخصصان بر بر اين

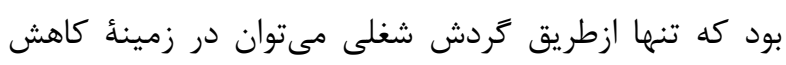

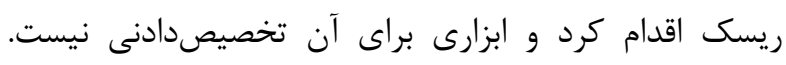
ايراتورهاى اين ايستخاه با وجود مصرف قرص مسكّن براى كاهش عوارض ناشى از كار، از گردش شغلى رضايت نداشتند.

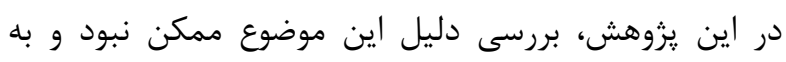

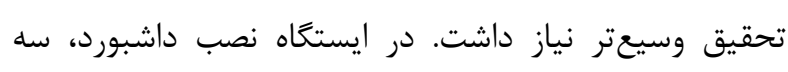

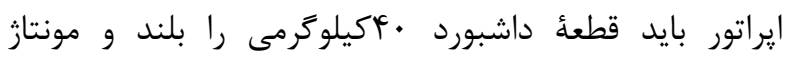
مى كردند. در اين ايستغاه، به استفاده از منىيليتور داشبورد احتياج بود كه امكان ساخت آن در داخل شركت با هزينهُ حدوداً

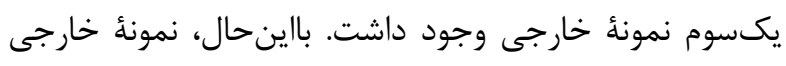

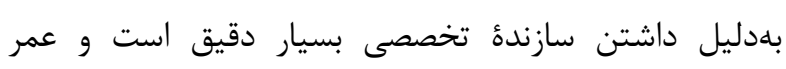
بيشترى نيز دارد. 
ايمن بودند. خطا در نصب بيجهاى مربوط به تايرها و اتصالات

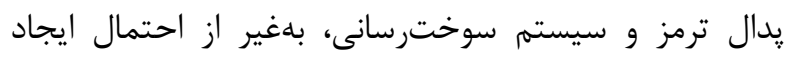

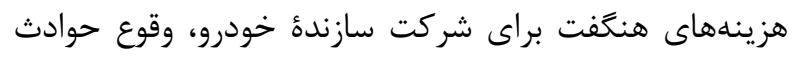

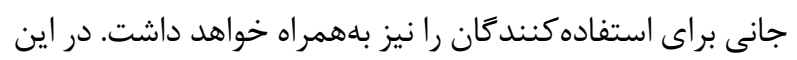

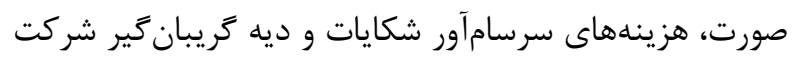

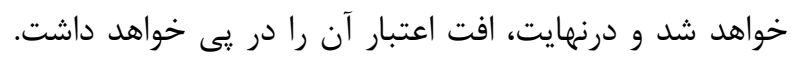

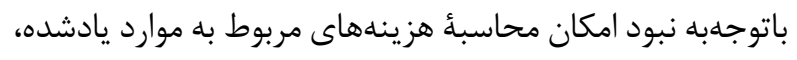

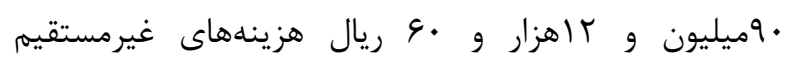
محاسبهشده درمقابل هزينههاى مستقيم بسيار ناجيز است.

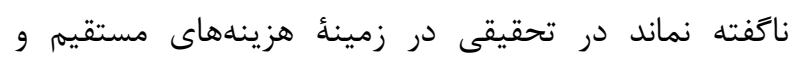

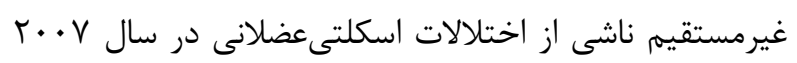

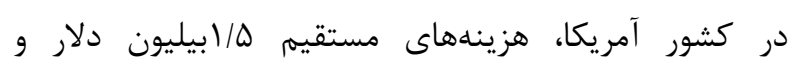

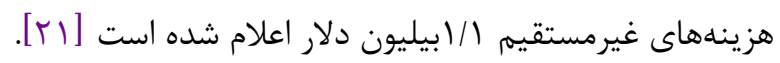

\section{نتيجه $\bar{~}$}

تاكنون، يزوهش داخلى در زمينه هزينهائهاى اختلالات

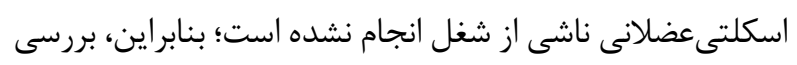

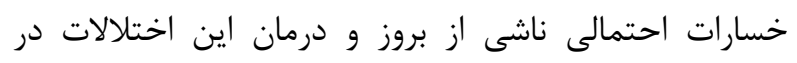

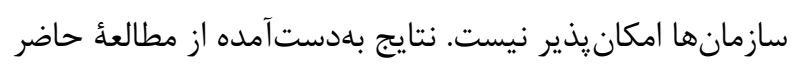

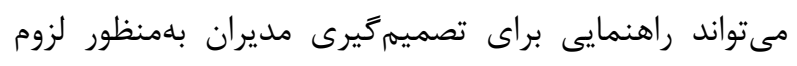

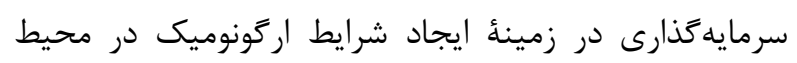

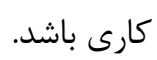

\section{تقدير و تشكر}

نويسند انان از تمامى كسانى تشكر و قدردانى مى كنند كه

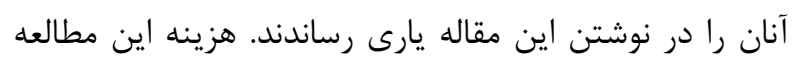

$$
\text { توسط نويسندًان تامين شده است. }
$$

\section{تعارض منافع}

بين نويسندكان اين مقاله هيج كونه تعارضى در منافع وجود

\section{References}

1. Piedrahita H. Costs of work-related musculoskeletal disorders (MSDs) in developing countries: Colombia case. Int J Occup Saf Ergon. 2006; $\quad 12(4)$ : $\quad 379-86$. [DOI:10.1080/10803548.2006.11076696] [PMID]

2. KARPIESIUK Ł. Automotive Industry Report. Warsaw: Polski Związek Przemysłu Motoryzacyjnego, Poland, 2015.
بهداشت وجود دارد؛ ولى در كشورهاى درحالتوسعه اين مؤسسهها وجود ندارد. همجنين، دسترسى به اطلاعات مربوط

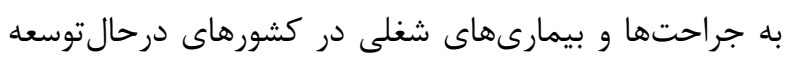

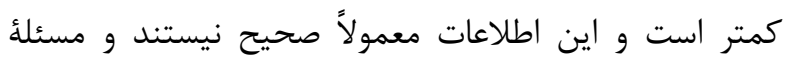

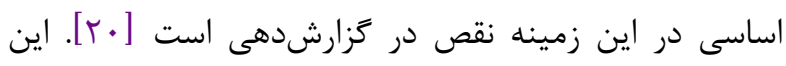
مسئله باعث مىشود كه مديران سازمان از بار اقتصادى اين حوادث دقيقاً مطلع نباشند.

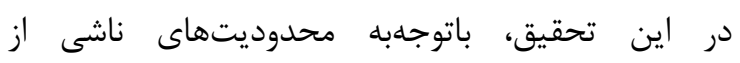

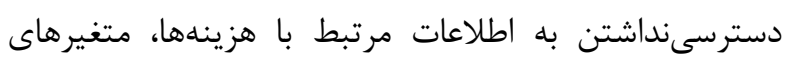
محدودى استخراجكردنى بود كه درنتيجه، مجموع هزينههاى بـى بـن

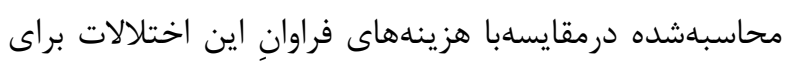

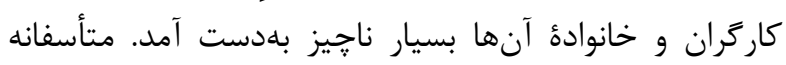

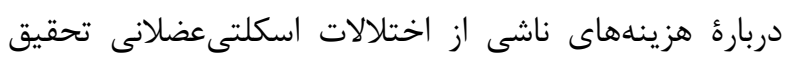

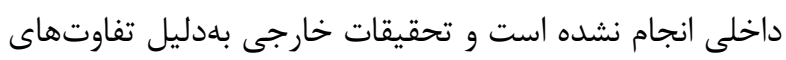
نظامهاى مالى و بيمه در آن كشورها درمقايسهبا ايران، مقايسهيذير يا استدلال كردنى نيستند. با تماس با جمعى از كارشناسان محترم سازمان تأمين ينان

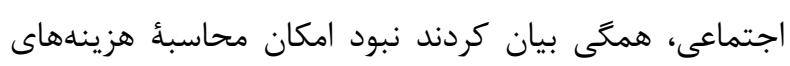

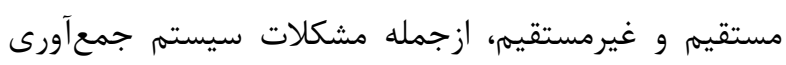

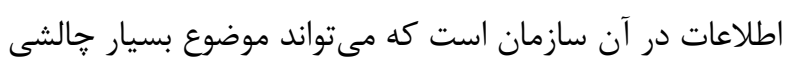

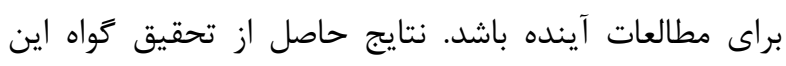

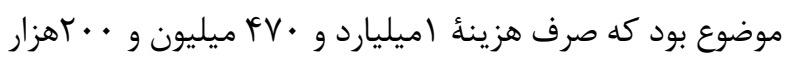
ريالى (درصورت ساخت منىيليتور داشبورد در داخل شركت)

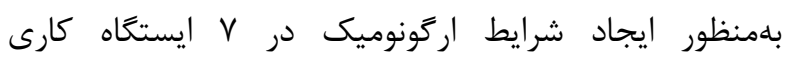

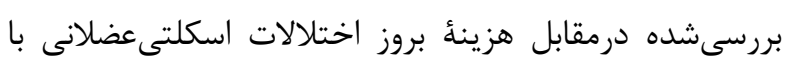

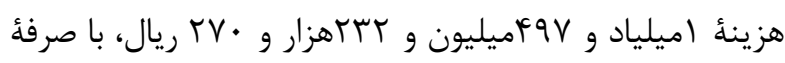
اقتصادى همراه است.

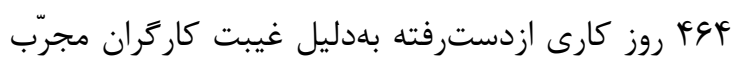
در V ايستخاه كارى مهم بهاحتمال زياد تأثير منفى بر كيفيت أرديت مونتاز محصولات و بهرهورى مى خذاشت كه بهدليل ثبتنشدن منان

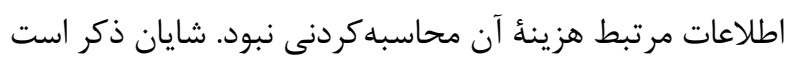

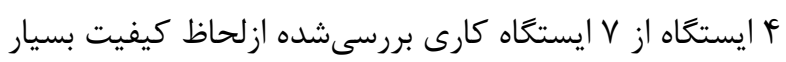

3. Błaszczyk A, Zygmańska-Jabłońska M, WegnerCzerniak K, Ogurkowska MB. Evaluating Progressive Overload Changes of the Musculoskeletal System in Automobile Industry Workers. Pol J Environ Stud. 2020; 29(4): 2579586. [DOI:10.15244/pjoes/111883]

4. Mattila MA, Vilkki M. OWAS methods. In: Karwowski W, Marras WS (Eds). The Occupational 
Ergonomics Handbook. USA: CRC Press LLC; 1999: 447-59.

5. Grandjean E, Kroemer KH. Fitting the task to the human: a textbook of occupational ergonomics. USA: CRC Press LLC; 1997. [DOI:10.1201/b16825] [PMCID]

6. Choobineh A. Methods of posture assessment in occupational ergonomics. Hamadan: Fanavaran; 2003:79-96.

7. Mattila M, Karwowski W, Vilkki M. Analysis of working postures in hammering tasks on building construction sites using the computerized OWAS method. Appl Ergon. 1993; 24(6):405-12. [DOI:10.1016/0003-6870(93)90172-6]

8. Dagenais S, Caro J, Haldeman S. A systematic review of low back pain cost of illness studies in the United States and internationally. Spine J. 2008; 8(1):8-20. [DOI:10.1016/j.spinee.2007.10.005] [PMID]

9. Atrkar Roshan S, Alizadeh SS. Estimate of economic costs of accidents at work in Iran: A case study of occupational accidents in 2012. Iran Occup Health. 2015; 12(1): 12-19.

10. Institute of Medicine, National Research Council, Commission on Behavioral and Social Sciences and Education, Panel on Musculoskeletal Disorders And the Workplace. Musculoskeletal disorders and the workplace: Low back and upper extremities. Washington (DC): National Academy Press; 2001.

11. Javan Noughabi J, Rezapour A, Setoodezadeh F, Moradpour AA. An Estimation of Direct and Indirect Costs for Elderly Patients in Tehran, 2015. Sadra Med Sci J. 2018; 6(1): 77-85.

12. Mohamadinejad A, Mortazavi SB, Jonidi Jafari A, Mofidi A. Estimation of direct and indirect costs of occupational injuries: A case study in one of the refining industries in Iran in 2015. Tibbi-i-kar J. 2020; 11(4): 57-71. [DOI:10.18502/tkj.v11i4.3651]

13. Vatani J, Razaei F. The relationship between the cost due to accidents in the drug industry and the investment in the Safety Management System. Arch Pharm Pract. 2017; 8(4): 104-08.

14. Garrouste-Orgeas M, Troché G, Azoulay E, Caubel A, de Lassence A, Cheval C, et al. Body mass index. An additional prognostic factor in ICU patients. Intensive Care Med. 2004; 30(3): 437-43. [DOI: 10.1007/s00134-003-2095-2] [PMID]

15. Kuorinka I, Jonsson B, Kilbom A, Vinterberg H, Biering-Sørensen F, Andersson G, et al. Standardised Nordic questionnaires for the analysis of musculoskeletal symptoms. Appl Ergon. 1987; 18(3):233-37. [DOI:10.1016/0003-6870(87)90010$\underline{\mathrm{X}}]$

16. Kivi P, Mattila M. Analysis and improvement of work postures in the building industry: application of the computerised OWAS method. Appl Ergon. 1991; 22(1): 43-48. [DOI:10.1016/00036870(91)90009-7]
17. Atrkar Roshan S, Alizadeh SS. Estimation of economic costs of accidents at work in Iran: A case study of occupational accidents in 2012. Iran Occup Health. 2015; 12(1): 12-19.

18. Berry L, Mirabito AM, Berwick DM. A health care agenda for business. MIT Sloan Manag Rev. 2004; 45(4): 56-64.

19. Tamin.ir. Iran: Salary tariff. 2018 April 29. https://tamin.ir/News/Item/58805/2/58805.html

20. Dorman P. Estimating the economic costs of occupational injuries and illnesses in developing countries: essential information for decisionmakers. Geneva, Switzerland: International Labour Organization; 2012.

21. Anderson N, Adams D, Bonauto D, Howard N, Silverstein B. Work-related musculoskeletal disorders of the back, upper extremity, and knee in Washington State, 2002-2010. Olympia, WA: Safety and Health Assessment and Research for Prevention (SHARP) Program, Washington State Department of Labor and Industries; 2015: 345. 